\title{
OVERVIEW CHARACTERISTICS AND P2Y12 REACTIVITY UNIT (PRU) VALUES OF ACUTE CORONARY SYNDROME AGE PRODUCTIVE PATIENTS WITH CLOPIDOGREL THERAPY
}

\author{
Rahmatini,* Gestina Aliska*, Masrul Syafri** \\ Department of Pharmacology Faculty of Medicine, Andalas University * \\ Department of Cardiology and Vascular Medicine Dr. M. Djamil Hospital/ Faculty of Medicine, Andalas \\ University** \\ Correspondence: Fk.unand.rahmatini@gmail.com
}

\begin{abstract}
Background: Ischemic heart disease is the leading cause of death and disability in the world with a fairly high portion coming from countries Low- and Middle-Income (LMICs). In Pakistan, 54\% patients acute coronary syndrome (ACS) was resistant to clopidogrel, and no data on clopidogrel resistance on ethnic Minang. This study aims to look at the characteristics and P2Y12 Reactivity Unit (PRU) from ACS patients in Dr. M. Djamil Hospital, Padang. Methods: This research is a cross sectional study. The effectiveness of clopidogrel on platelet reactivity identified through examination of PRU value using VerifyNow ${ }^{\circledR}$ with a cutoff point is 208. From the PRU values, it can be classified whether patients resistant or responsive. The study was conducted in September 2016. Result: From 14 patients with ACS who received clopidogrel, 11 patients (78.57\%) are male with 3 female patients (21.43). The mean of age was 53.78 years old. Patients mostly came from West Sumatra provinces $(92,85 \%)$ and $7,15 \%$ from others. From all of patients head risk factors of coronary arterial disease. Hipertension was the greatest risk factor. Conclusion: It can be concluded that most of the patients were male. From PRU data, 7 patients (50\%) were resistant and 7 patients $(50 \%)$ were response to clopidogrel. Further research is needed with larger numbers of patients and investigate pharmacogenetic profile of CYP2C19 as caused of resistance.
\end{abstract}

Keyword : PRU, Acute coronary syndrome, Clopidogrel

\section{PENDAHULUAN}

Penyakit jantung iskemik merupakan penyebab utama kematian dan kecacatan di seluruh dunia. Kejadian penyakit jantung iskemik ditemukan dengan posrsi cukup tinggi berasal dari negaranegara dengan pendapatan perkapita rendah sampai sedang, atau disebut Low-Middle Income Countries (LMICs). Sebuah penelitian yang dilakukan di Pakistan, menunjukkan 54\% pasien dengan sindrom koroner akut atau acute coronary syndrome (ACS) adalah tahan terhadap clopidogrel. sampai saat ini belum ada penelitian ataupun data tentang ketahanan clopidogrel pada masyarakat Indonesia khususnya etnis Minang.

Penelitian ini bertujuan untuk melihat karakteristik dan P2Y12 Reaktivitas Unit (PRU) dari pasien ACS di Rumah Sakit Dr. M. Djamil, Padang.

\section{METODE PENELITIAN}

Penelitian ini merupakan studi cross sectional, dilakukan pada bulan September 2016 di Rumah Sakit Dr. M. Djamil Padang. Jumlah sampel yang diteliti adalah 14 orang yang terdiri dari 14 pasien sindrom koroner akut atau acute coronary syndrome (ACS yang menerima clopidogrel. dari 14 pasien tersebut 11 pasien $(78,57 \%)$ adalah laki-laki dengan 3 pasien perempuan $(21,43)$.

Efektivitas clopidogrel pada reaktivitas platelet diidentifikasi dengan melakukan pemeriksaan nilai PRU menggunakan VerifyNow dengan titik cut-off adalah 208. Dari hasil pemeriksaan didapatkan nilai PRU, yang selanjutnya diklasifikasikan apakah pasien resisten atau responsif.

\section{HASIL PENELITIAN}

Telah didapatkan sebanyak 30 orang pasien yang memenuhi kriteria penelitian dan telah 
menandatangani inform consent. Sebanyak 2 ( dua ) orang pasien diekslusi karena tidak didapatkan nilai PRU pada pemeriksaan darah, pasien menolak diambil darah ulang. Data yang baru kami analisis sementara melibatkan 14 orang pasien dan 16 orang pasien lainnya menyusul di laporan akhir. Data 14 orang pasien tersebut dengan sindrom koroner akut, yang dirawat di Rumah Sakit Dr. Djamil M, Padang. Variasi dari subjek rentang usia dengan usia rata-rata 45-60 tahun adalah 53,78\%. Subjek laki-laki sebanyak $(78,57 \%)$ dan perempuan $(21,43 \%)$. Sebagian besar pasien berasal dari provinsi Sumatera Barat dan hanya 1/14 dari luar provinsi. Dari 14 pasien, semuanya memiliki faktor risiko penyakit arteri koroner (CAD), Hipertensi adalah faktor risiko terbesar dari CAD (78,57\%) pada pasien. (Tabel 1)

Tabel 1. Karakteristik awal dari pasien

\begin{tabular}{|c|c|}
\hline Variabel & Pasien $(n=14)$ \\
\hline Usia, Tahun * & $53.78(45-60)$ \\
\hline \multicolumn{2}{|l|}{ Jenis Kelamin } \\
\hline Laki - Laki & 11/14 (78.57\%) \\
\hline Perempuan & $3 / 14(21.43 \%)$ \\
\hline \multicolumn{2}{|l|}{ Asal } \\
\hline Sumatera Barat & $13 / 14(92.85 \%)$ \\
\hline \multicolumn{2}{|l|}{ Luar Provinsi } \\
\hline \multicolumn{2}{|l|}{ Faktor Risiko } \\
\hline \multirow{2}{*}{$\mathrm{Ya}$} & $14 / 14(100 \%)$ \\
\hline & $0 / 14(0 \%)$ \\
\hline \multicolumn{2}{|l|}{ Perokok } \\
\hline $\mathrm{Ya}$ & $8 / 14(57.14 \%)$ \\
\hline Tidak & $6 / 14(42.85 \%)$ \\
\hline \multicolumn{2}{|l|}{ Hipertensi } \\
\hline $\mathrm{Ya}$ & $11 / 14(78.57 \%)$ \\
\hline Tidak & $3 / 14(21.43 \%)$ \\
\hline \multicolumn{2}{|l|}{ Diabetes Melitus } \\
\hline $\mathrm{Ya}$ & $3 / 14(21.43 \%)$ \\
\hline Tidak & $11 / 14(78.57 \%)$ \\
\hline \multicolumn{2}{|l|}{ Dyslipidemia } \\
\hline $\mathrm{Ya}$ & $2 / 14(14.28 \%)$ \\
\hline Tidak & $12 / 14(85.72 \%)$ \\
\hline \multicolumn{2}{|l|}{ Menopause } \\
\hline $\mathrm{Ya}$ & $2 / 14(13.3 \%)$ \\
\hline Tidak & $1 / 14(7.15 \%)$ \\
\hline
\end{tabular}

Berdasarkan nilai P2Y12 Reaktivitas Unit (PRU), 50\% pasien memiliki nilai > 208 yang diklasifikasikan sebagai pasien resisten dan 50\% pasien dengan nilai PRU $<208$ yang diklasifikasikan sebagai pasien responsif (Gambar $1)$.

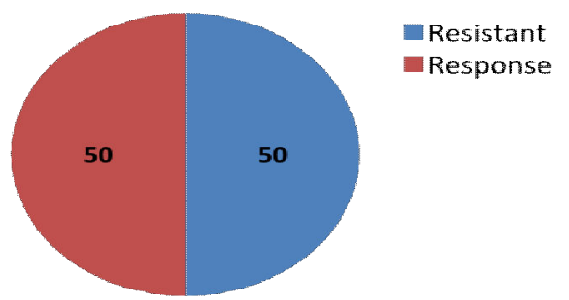

Gambar 1. Nilai dari PRU Berdasarkan Potong Titik

\section{PEMBAHASAN}

Dari hasil, semua pasien studi berusia di atas 40 tahun. Ada berbagai faktor risiko yang menyebabkan rentan terhadap penyakit. Sebagian besar SKA merupakan manifestasi akut arteri koroner plak ateromatosa robek atau pecah. Acara ini akan diikuti oleh proses agregasi platelet dan aktivasi jalur koagulasi. Membentuk trombus yang kaya platelet (trombus putih). trombus ini akan menyumbat lubang arteri koroner, baik total atau sebagian. Beberapa faktor ekstrinsik, seperti demam, anemia, tirotoksikosis, hipotensi, takikardia, dapat memicu terjadinya ACS pada pasien yang sudah memiliki plak aterosklerosis. (PERKI, 2015)

Sesuai dengan literatur, pasien dengan sindrom koroner akut didominasi oleh laki-laki gender.In penelitian ini juga menemukan faktor-faktor risiko lain seperti diabetes, hipertensi, dislipidemia dan menopause. resistensi clopidogrel adalah suatu kondisi yang clopidogrel kurang efektif dari normal pada orang yang diperlakukan dengan it.7 Dalam penelitian ini kami menemukan (40\%) resistensi clopidogrel. Orang dengan resistensi clopidogrel yang menerima clopidogrel beresiko komplikasi serius,kadang-kadang fatal,. Orang-orang ini mungkin memiliki serangan jantung atau stroke yang disebabkan oleh pembentukan gumpalan darah abnormal; mereka dengan stent dapat mengembangkan bekuan darah (trombosis) dalam stent, menghambat aliran darah. 


\section{KESIMPULAN}

Dalam penelitian ini kami menemukan (60\%) dari subjek masih responsif. Varian gen modulasi penyerapan clopidogrel Dan metabolisme juga dapat berdampak pada clopidogrel response.7,8.

\section{PENGAKUAN}

Penelitian ini didukung oleh Departemen Farmakologi dan Terapeutik Fakultas Kedokteran, Universitas Andalas (FMAU) dan Departemen Kardiologi dan Kedokteran Vaskular RS dr. M. Djamil / FMAU.

\section{DAFTAR PUSTAKA}

Vedanthan R,Seligman B, Fuster V. Global perspective on acute coronary syndrome: a burden on the young and poor. Circ Res. 2014;114:1959-75

Melati R, Basuki E, Setianto B. Relationship between job strain and myocardial infarction in the national cardiovascular center patient. J Kardiol Ind. 2008; 29: 12-19.

British Nutrition Foundation, 2013. Nutrition and development: short an long term consequences for your health. British: blackwell publishing Ltd.

Ogawa $\mathrm{H}$, Isshiki $\mathrm{T}$, Kimura $\mathrm{T}$, Yokoi $\mathrm{H}$, Nanto $\mathrm{S}$, Takayama M, et al. Effects of CYP2C19 allelic variants on inhibition of platele aggregation and major adverse cardiovascular events in Japanese patients with acute coronary syndrome: The PRASFIT-ACS study. J Cardiol. 2016;68:29-36.
González A, Moniche F, Cayuela A, García-Lozano JR, Torrecillas F, Escudero-Martínez I, et al. Effect of CYP2C19 Polymorphisms on the Platelet Response to Clopidogrel and Influence on the Effect of High Versus Standard Dose Clopidogrel in Carotid Artery Stenting. Eur J Vasc Endovasc Surg. 2016;51:175-86.

Rehman KU, Akhtar T, Sabar MF, Tariq MA. Allele frequency distribution of CYP2C19*2 allelic variants associated with clopidogrel resistance in cardiac patients. Exp Ther Med. 2015;10:309-15.

PERKI (2015). Pedoman Tata Laksana Sindrom Koroner Akut. Perhimpunan Dokter Spesialis Kardiovaskular Indonesia. Centra Communications. Edisi I. Hal 11-35.

Nguyen TA, Diodati JG, Pharand C. Resistance to clopidogrel: a review of the evidence. J Am Coll Cardiol. 2005;45:1157-64.

Genetic variability in response to clopidogrel therapy and its clinical implications. Thrombosis and haemostasis suplemen.2011; 1.p.555-559. 